\title{
MLC60I in vascular dementia: an efficacy and safety pilot study
}

\author{
This article was published in the following Dove Press journal: \\ Neuropsychiatric Disease and Treatment \\ 5 October 2017 \\ Number of times this article has been viewed
}

\author{
Hossein Pakdaman' \\ Ali Amini Harandi' \\ Koroush Gharagozli' \\ Mehdi Abbasi' \\ Majid Ghaffarpour ${ }^{2}$ \\ Farzad Ashrafi' \\ Hosein Delavar Kasmaei ${ }^{1}$ \\ Asghar Amini Harandi ${ }^{3}$ \\ 'Brain Mapping Research Center, \\ Shahid Beheshti University of Medical \\ Sciences, Tehran, Iran; '2Iranian Center \\ of Neurological Research, Imam \\ Khomeini Hospital, Tehran University \\ of Medical Sciences, Tehran, Iran; \\ ${ }^{3}$ Department of Biochemistry, School \\ of Medicine, Jiroft University of \\ Medical Sciences, Jiroft, Iran
}

Background and aim: Vascular dementia $(\mathrm{VaD})$ is the second most common cause of dementia and currently there is scarcity of therapies for $\mathrm{VaD}$. We aimed to investigate the efficacy and safety of MLC601 in the treatment of VaD.

Methods: In this multicenter, pilot, randomized, double-blind trial, 82 patients with VaD according to DSM-5 criteria received MLC601 or placebo capsules three times a day for 2 years. The primary efficacy end-point was evaluated by comparing Mini-Mental State Examination (MMSE) and Alzheimer's Disease Assessment Scale-cognitive subscale (ADAS-cog) score between the two groups over 2 years of study. Safety was also assessed by recording adverse events and abnormal laboratory results.

Results: Eighty-one patients completed the study and were included in the analysis. One patient was lost to follow-up in the placebo group. After 2 years, mean $( \pm \mathrm{SD})$ changes in the MMSE score were $-3.71( \pm 4.50)$ for MLC601 group and $-9.33( \pm 4.80)$ for placebo group. ADAS-cog score showed $( \pm \mathrm{SD})$ changes of $7.34( \pm 9.55)$ and $19.00( \pm 11.28)$ for MLC601 and placebo group, respectively. Repeated measures analyses showed that both MMSE and ADAS-cog scores were significantly better in the treatment group at 24 months $(p<0.001)$. Ten $(24.39 \%)$ patients reported predominantly transient gastrointestinal adverse events in MLC601 group. No patient left the study due to adverse events. There were no clinically significant abnormalities on laboratory tests.

Conclusion: Patients treated with MLC601 over the 2 years showed dramatically better cognitive outcome compared with those treated with placebo. MLC601 was devoid of any serious adverse events and was well-tolerated.

Keywords: vascular dementia, MLC601, safety, randomized placebo-controlled trial

\section{Introduction}

Vascular dementia $(\mathrm{VaD})$ is the second most common cause of dementia following Alzheimer's disease in elderly people, and it accounts for approximately $15 \%-20 \%$ of dementia cases. ${ }^{1-3}$ Essentially, the treatment of $\mathrm{VaD}$ is confined to stratification of underlying cerebrovascular risk factors, and there is no approved or recommended drug therapy. The absence of effective treatments creates a burden for those suffering from the disease, their caregivers, and health care providers. ${ }^{4}$ Although cholinergic dysfunction has been implicated in VaD neuropathology, ${ }^{5-7}$ clinical trials have indicated that acetylcholinesterase inhibitors have small or uncertain clinical benefit in patients with VaD. ${ }^{8,9}$ Also, trials evaluating the efficacy of memantine (N-Methyl-D-aspartate receptor antagonist) in $\mathrm{VaD}$ have shown limited clinical benefit. ${ }^{9,10}$

MLC601 (NeuroAiDTM; Moleac Pte. Ltd, Singapore) is a natural medicine that contains both herbal and nonherbal components, having some neuroprotective and neurorestorative properties. ${ }^{11}$ It has been shown to protect the brain from ischemic
Correspondence: Ali Amini Harandi Brain Mapping Research Center, Loghman Hakim Hospital, Shahid Beheshti University of Medical Sciences, Makhsoos St, South Kargar Ave, Tehran, Iran Mobile +989126026214 Email ali.amini@sbmu.ac.ir $\mathrm{BY}$
he hereby accept the Terms. Non-commercial uses of the work are permitted without any further permission from Dove Medic
for commercial use of this work, please see paragraphs 4.2 and 5 of our Terms (https://www.dovepress.com/terms.php). 
injury, improve survival and reduce functional deficits in animal models of stroke. Additionally, MLC601 has been demonstrated to induce neurogenesis, promote cell proliferation and development of dense axonal-dendritic network in animal models, thus, helping in the restoration of neurological function. Current literature reports positive results with MLC601 in post-stroke recovery, Alzheimer's disease and mild cognitive impairment (MCI). ${ }^{12-16}$ Also, the ongoing NEURITES study is investigating the effect and tolerability

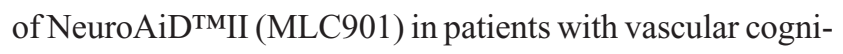
tive impairment. ${ }^{17}$

The present study was conducted to determine efficacy and safety of MLC601 in patients suffering from VaD. The rationale behind this study is based on the neuroprotective and neurorestorative properties of MLC601 and growing evidence of its effectiveness in long-term post-stroke recovery ${ }^{16}$ and dementia supportive treatment. ${ }^{13,14}$ Therefore, we can hypothesize that MLC601 may help with the conundrum of $\mathrm{VaD}$ treatment, and prevention of further deterioration.

\section{Patients and methods}

\section{Study design}

This multicenter, pilot, randomized, double-blind, placebocontrolled study was carried out to assess the efficacy and safety of MLC601 in VaD with a 2-year follow-up period from October 2014 to January 2017.

After obtaining written informed consent and registering the trial in the local registry at Sahid Behesti University of Medical Sciences, initial screening of patients referred to our center was performed. Included patients were randomly assigned to either MLC601 arm consisting of treatment with MLC601 capsules (NeuroAiD ${ }^{\mathrm{TM}}$; 0.4 g per capsule) or control arm consisting of treatment with identical-appearance placebo capsules. In each group, every patient received one capsule three times a day in addition to their prescribed medications, and no modification was made in their treatment regimen.

MLC601 capsules included nine herbal components and five non-herbal components. ${ }^{12}$ The visually identical placebo capsules contained inert substances (dried ripe fruits, flour) with no active therapeutic effect. Each patient received capsules in containers labeled with their name and allocated number. Randomization was conducted using computergenerated protocol.

Patients, caregivers, and investigators involved in the study were blinded to the treatment groups. Demographic and clinical characteristics of the patients were documented at baseline. Patients were assessed at baseline and subsequent months 6, 12, 18, and 24. During clinical visits, patients underwent an evaluation: physical examination including thorough neurological examination, and cognitive function assessments. Additionally, laboratory tests assessments including blood count, renal function test, and liver function test, as well as adverse events monitoring were conducted during follow-up visits.

\section{Patients}

Between October 2014 and January 2015, patients suffering from $\mathrm{VaD}$ diagnosed by DSM-5 criteria for $\mathrm{VaD}$ were recruited for our study if they fulfilled the following inclusion criteria: age $>55$ years, score of $\geq 10$ on Mini-Mental State Examination (MMSE), Alzheimer's Disease Assessment Scale-cognitive subscale (ADAS-cog) $>12$, no history of Alzheimer's disease or other types of dementia, no history of seizure or alcohol addiction or drug abuse, not suffering from psychotic episodes, vascular lesions depicted by computerized tomography (CT) scan or magnetic resonance imaging (MRI). Exclusion criteria were: severe or unstable underlying disease, use of conventional anti-dementia drugs including cholinesterase inhibitors and memantine, significant non-ischemic brain lesions on CT scan or MRI.

\section{Efficacy assessments}

Efficacy measures utilized in this study for evaluating cognitive function were MMSE and ADAS-cog. MMSE evaluates several domains, and its score ranges from 0-30 with higher scores indicating better cognitive function. ${ }^{18}$ ADAS-cog is composed of seven short cognitive tests and four scales, and its global score ranges from 0-70 (the higher the score, the worse the cognitive function). ${ }^{19}$ The efficacy end-points of the study were to compare the changes in MMSE and ADAS-cog scores between the MLC601 and the placebo group at each time-point of the follow-up period, ie, at $6,12,18$ and 24 months.

\section{Safety assessment}

Safety was evaluated by recording the frequency of adverse events reported by patients or their caregiver on each follow-up visit. Moreover, any abnormality in scheduled, follow-up laboratory tests including blood count, liver, and renal function tests were recorded.

\section{Statistical analysis}

Statistical analyses were carried out by using SPSS 18.0 (SPSS Inc., Chicago, IL, USA). The independent $t$-test, the chi-square test, and the general linear model (repeated measures) were used to interpret data. All tests were conducted at the level of 0.05 significance. 


\section{Ethical issues}

Prior to inclusion in the trial, each subject and his/her caregiver were required to provide written informed consent. Patients were also allowed to continue taking their previously prescribed medications. This trial was conducted in accordance with the Helsinki Declaration, and was approved by the Ethics Committee at Shahid Beheshti University of Medical Sciences.

\section{Results}

\section{Baseline characteristics}

Of 202 candidates screened, 82 patients fulfilled the criteria and entered the study. Eighty-one patients completed the study and one patient in the placebo group was excluded since he did not attend any follow-up visits. The study flowchart is depicted in Figure 1.

At baseline, there was no statistically significant difference between MLC601 and placebo group with respect to age, gender, marital status, medical history, MMSE scores, ADAS-cog scores and concomitant drug therapy (Tables 1 and 2), additionally Table 3 summarizes MRI findings of both groups.

\section{Efficacy outcomes MMSE score}

The mean MMSE scores and the mean changes from baseline at follow-up visits are depicted in Table 4. Over the course of our 24 months of observation, the mean changes $( \pm \mathrm{SD})$ in the MMSE score for the MLC601 and

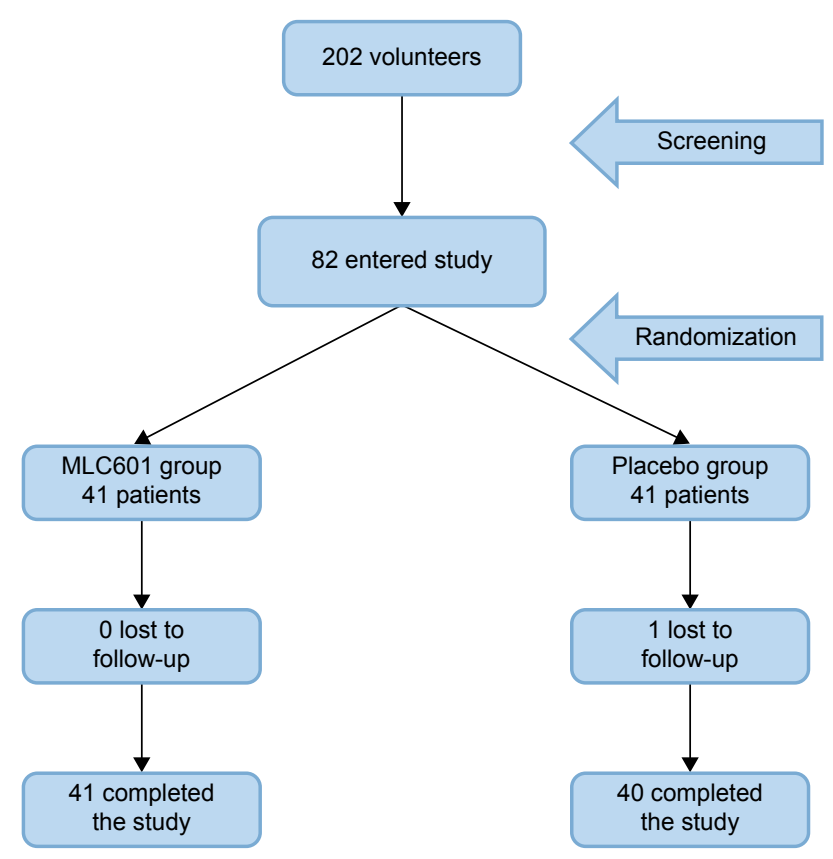

Figure I Study flowchart.
Table I Baseline characteristics

\begin{tabular}{|c|c|c|c|}
\hline Variable & $\begin{array}{l}\text { MLC60I } \\
(n=4 I)\end{array}$ & $\begin{array}{l}\text { Placebo } \\
(n=40)\end{array}$ & $p$-value \\
\hline Age, mean $\pm S D$, years & $72.12( \pm 4.81)$ & $74.08( \pm 4.66)$ & 0.07 \\
\hline Gender (males) & $24(58.5 \%)$ & $21(52.5 \%)$ & 0.66 \\
\hline Marital status (married) & $35(85.37 \%)$ & $28(70 \%)$ & 0.096 \\
\hline \multicolumn{4}{|l|}{ Education, $\mathrm{n}$} \\
\hline Illiterate & 0 & I & \\
\hline Lettered & 2 & 4 & 0.162 \\
\hline Middle school & 10 & 5 & \\
\hline Diploma & 19 & 14 & \\
\hline College & 9 & 17 & \\
\hline \multicolumn{4}{|l|}{ Medical history, $\mathrm{n}$} \\
\hline Ischemic heart disease & 23 & 25 & 0.65 \\
\hline Hypertenstion & 25 & 26 & 0.81 \\
\hline Dyslipidemia & 15 & 13 & 0.81 \\
\hline Diabetes mellitus & 17 & 14 & 0.64 \\
\hline Smoking & 4 & 3 & 0.73 \\
\hline MMSE score, mean \pm SD & $21.12( \pm 2.19)$ & $21.28( \pm I .8 I)$ & 0.73 \\
\hline ADAS-cog score, mean \pm SD & $22.82( \pm 3.57)$ & $22.30( \pm 2.83)$ & 0.46 \\
\hline
\end{tabular}

Abbreviations: MMSE, Mini-Mental State Examination; ADAS-cog, Alzheimer's Disease Assessment Scale-cognitive subscale.

placebo group were $-3.71( \pm 4.50)$ and $-9.33( \pm 4.80)$ respectively. By the general linear model, the repeatedmeasures analysis was performed based on the MMSE score, and it revealed a statistically significant difference between the placebo and the MLC601 group during the study period $(p<0.001)$ (Figure 2$)$. Additionally, statistical significance difference was first noticed at 6 month follow-up visit $(p=0.001)$.

\section{ADAS-cog score}

The mean ADAS-cog scores and the mean changes from baseline at follow-up visits are shown in Table 5. During the follow-up period, the mean changes $( \pm \mathrm{SD})$ in ADAS-cog score for the MLC601 and placebo group were $7.34( \pm 9.55)$ and $19.00( \pm 11.28)$, respectively. Based on ADAS-cog score, repeated-measures analysis (general linear model) revealed a statistically significant difference between the placebo and the MLC601 group during the study period

Table 2 Concomitant drug therapy during study

\begin{tabular}{lll}
\hline Medications & MLC60I, n & Placebo, n \\
\hline Antithrombotic agents & 32 & 31 \\
ACE inhibitor or ARB & 27 & 28 \\
Beta blocker & 16 & 15 \\
Calcium channel blockers & 10 & 11 \\
Lipid lowering agents & 34 & 33 \\
Diuretics & 8 & 9 \\
Nitrates & 23 & 25
\end{tabular}

Abbreviations: ACE, angiotensin-converting-enzyme; ARB, angiotensin receptor blockers. 
Table 3 MRI findings in MLC60I and placebo group

\begin{tabular}{lll}
\hline Variable & $\begin{array}{l}\text { MLC60I } \\
(\mathbf{n = 4})\end{array}$ & $\begin{array}{l}\text { Placebo } \\
(\mathbf{n = 4 0 )}\end{array}$ \\
\hline Unilateral large-vessel lesions & 14 & 18 \\
Bilateral large-vessel lesions & 1 & 2 \\
Frontal WML & 9 & 13 \\
Extensive periventricular WML & 20 & 18 \\
Basal ganglia & 16 & 15 \\
Bilateral thalamic lesions & 3 & 2 \\
Multiple white matter infarcts & 3 & 3 \\
Bilateral cortical infarcts & 2 & 3 \\
\hline
\end{tabular}

Abbreviations: MRI, magnetic resonance imaging; WML, white matter lacune.

$(p<0.001)$ (Figure 3). Also, the difference became significant at 6 month follow-up visit $(p=0.002)$.

\section{Safety outcome}

In MLC601 group, 10 (24.39\%) patients reported predominantly transient gastrointestinal adverse events including abdominal cramp (4, 9.7\%), abdominal discomfort $(4,9.7 \%)$, nausea $(3,7.3 \%)$, abdominal pain $(2,4.8 \%)$ and lack of appetite (2, 4.8\%). One patient in the MLC601 group and two patients in the placebo group had a new stroke over the course of the 2 years of follow-up. No patient left the study due to adverse events. There was no abnormal alteration in the blood cell count and renal and liver function tests. In the placebo group, no other adverse events were recorded.

\section{Discussion}

The current guidelines pertaining to $\mathrm{VaD}$ treatment are confined to stratification of risk factors related to cerebrovascular disease. Also, evidence that certain medication could help in $\mathrm{VaD}$ treatment is limited and inconclusive, ${ }^{8,9}$ and their role in the $\mathrm{VaD}$ remains to be elucidated.

In this study, MLC601 showed considerable benefit over placebo in patients suffering from VaD. Additionally, the MLC601 safety profile demonstrated no significant adverse events except for some transient gastrointestinal

Table 4 Mean \pm SD of MMSE scores in MLC60I and placebo group

\begin{tabular}{lllll}
\hline & MLC60I & Placebo & $\begin{array}{l}\text { Mean } \\
\text { difference }\end{array}$ & P-value \\
\hline Baseline & $21.12( \pm 2.19)$ & $21.28( \pm I .8 I)$ & 0.15 & 0.73 \\
6 months & $21.37( \pm 3.43)$ & $18.95( \pm 3.06)$ & $-2.4 \mathrm{I}$ & $0.00 \mathrm{I}$ \\
12 months & $20.34( \pm 2.98)$ & $15.90( \pm 4.06)$ & -4.44 & $<0.00 \mathrm{I}$ \\
18 months & $18.98( \pm 3.33)$ & $13.90( \pm 4.62)$ & -5.07 & $<0.00 \mathrm{I}$ \\
24 months & $17.4 \mathrm{I}( \pm 3.75)$ & $1 \mathrm{I} .95( \pm 4.64)$ & -5.46 & $<0.00 \mathrm{I}$ \\
\hline
\end{tabular}

Abbreviation: MMSE, Mini-Mental State Examination.

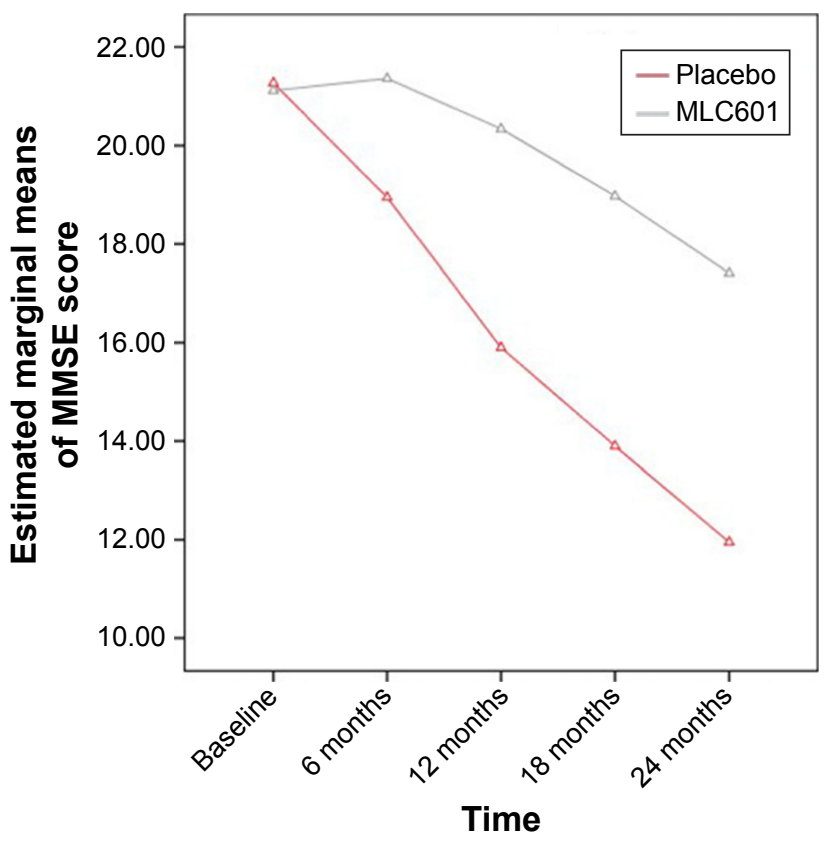

Figure 2 Mean changes in MMSE score in the MLC60I and placebo groups. 95\% confidence interval for difference (2.16 to 4.73).

Abbreviation: MMSE, Mini-Mental State Examination.

symptoms that were well-tolerated, no patient left the study due to adverse events. Based on both cognitive function scores, the observed difference between two groups became statistically significant at 6 month follow-up visit and remained significant during the next visits. This early response to MLC601 could arise from its neuroprotective and neuroregenerative properties. ${ }^{12}$ In a study of a rat model of traumatic brain injury (TBI), ${ }^{20}$ it was revealed that MLC 901 decreased brain lesions following TBI, reduced infarct volume, and prevented the formation of edema. These results were associated with up-regulation of vascular endothelial growth factor (VEGF). Additionally, MLC901 decreased cognitive impairment following TBI. Authors concluded that these findings indicate neuroprotective and neurorestorative properties of MLC $901 .{ }^{20}$ In another animal study in normal, non-injured mice, ${ }^{21}$ MLC901 promotes extinction in passive avoidance and reversal learning in the Morris

Table 5 Mean and standard deviations of ADAS-cog scores in MLC60I and placebo group

\begin{tabular}{lllll}
\hline & MLC60I & Placebo & $\begin{array}{l}\text { Mean } \\
\text { difference }\end{array}$ & p-value \\
\hline Baseline & $22.82( \pm 3.57)$ & $22.30( \pm 2.83)$ & -0.52 & 0.46 \\
6 months & $22.36( \pm 6.12)$ & $26.45( \pm 5.02)$ & 4.08 & 0.002 \\
I2 months & $24.12( \pm 5.45)$ & $31.87( \pm 8.16)$ & 7.75 & $<0.001$ \\
I8 months & $26.87( \pm 7.07)$ & $35.87( \pm 9.40)$ & 8.99 & $<0.001$ \\
24 months & $30.17( \pm 8.90)$ & $41.30( \pm 10.98)$ & 11.12 & $<0.001$ \\
\hline
\end{tabular}

Abbreviation: ADAS-cog, Alzheimer's Disease Assessment Scale-cognitive subscale. 


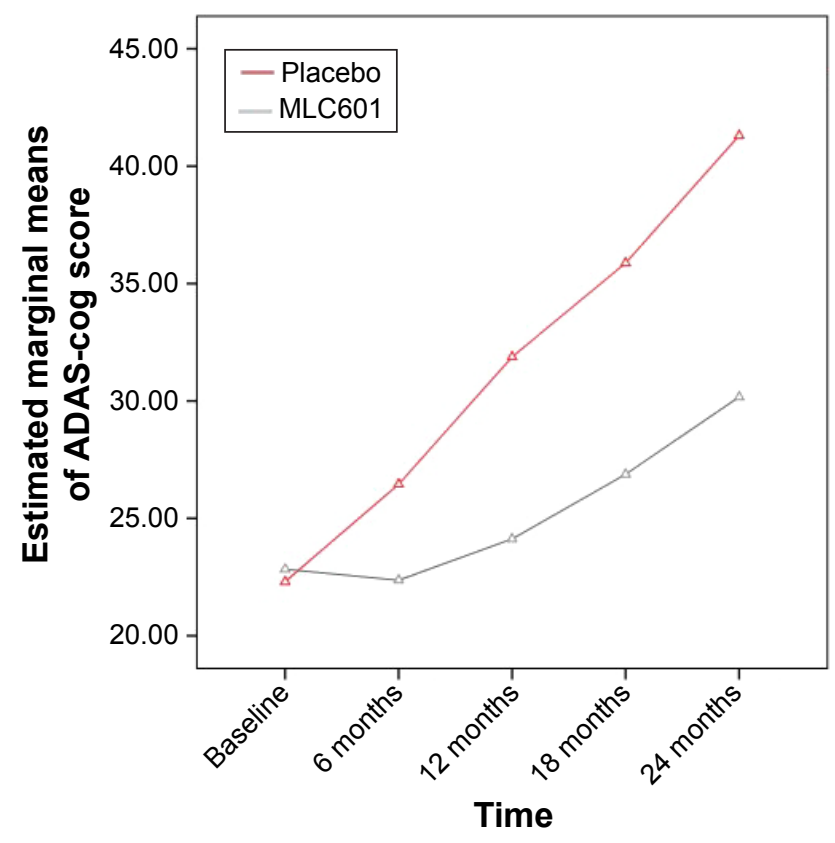

Figure 3 Mean changes in ADAS-cog scores in the MLC60I and placebo groups. $95 \%$ confidence interval for difference $(-8.87$ to -3.70$)$.

Abbreviation: ADAS-cog, Alzheimer's Disease Assessment Scale-cognitive subscale.

water maze (hippocampus-dependent cognitive task) and improves the performance of mice in novel object recognition (hippocampus-independent cognitive task). Also, the long-term proneurogenesis effects of MLC901 increase the number of mature neurons in the hippocampus. ${ }^{21}$

To date, no study has been published that evaluated the efficacy and safety of MLC601 in VaD treatment. Hence, no direct comparison between our findings and other studies is conceivable. However, compared to previous studies on MLC601 in dementia, ${ }^{14,15}$ our study findings on VaD are promising.

Furthermore, when compared to previous studies on memantine and acetylcholinesterase inhibitors, in our study MLC601 has depicted better cognition outcome with fewer, and transient, adverse events.

In a double-blind, placebo control trial of 592 patients by Erkinjuntti et al, ${ }^{22}$ it was revealed that during 6 months of follow-up galantamine was superior to placebo regarding ADAS-cog score with 2.7 score difference between the two groups. However, discontinuation rates were $19.7 \%$ and $8.2 \%$ in the galantamine and placebo groups, respectively. The authors reported that gastrointestinal symptoms, mostly happened during the dose-escalation phase, were the most common adverse events and were mild-to-moderate in severity. In the study, galantamine depicted lower ADAS-cog score difference when compared with MLC601 in our study, over 6 months (2.7 for galantamine and 4.08 for MLC601). ${ }^{22}$
Additionally, MLC601 had fewer adverse events, and no patient left the study. Another randomized control trial of galantamine with a 26 week follow-up period ${ }^{23}$ showed that galantamine had improved cognition outcome with 1.5 ADAS-cog score difference between the galantamine and placebo groups. Discontinuation rates were $13 \%$ and $6 \%$ in the galantamine and placebo groups, respectively, and $20 \%$ of patients experienced serious adverse events. Compared to this galantamine study, our present study with MLC601 showed better cognition outcome measured by ADAS-cog score and serious adverse events were not recorded for MLC601. ${ }^{23}$ Donepezil, another acetylcholinesterase inhibitor, also showed inferior cognition outcomes compared with MLC601 in our study. In a 24 week randomized control trial of donepezil, the authors reported 1.65 and 2.09 difference in ADAS-cog score for donepezil $5 \mathrm{mg}$ and donepezil $10 \mathrm{mg}$, respectively. It is also reported that half of discontinuation is due to emergent adverse events, and serious adverse events occurred in $13.5 \%$ and $14.4 \%$ of patients treated with $5 \mathrm{mg}$ and $10 \mathrm{mg}$ doses, respectively. ${ }^{24}$ Interestingly, when compared with MLC601 in this study, memantine also depicted lower cognition function improvement measured by ADAS$\operatorname{cog}$ score. In a study by Orgogozo et a ${ }^{10}$ after 28 weeks of follow-up, 2.0 score difference in ADAS-cog score and 1.71 score difference in MMSE between memantine and placebo group, were reported. Twenty-five percent serious adverse events were recorded as well. ${ }^{10}$ Another study with the same follow-up period also revealed no better cognition outcome measured by ADAS-cog score (1.75 score difference between memantine and placebo group) and adverse events were recorded in about $75 \%$ of patients treated with memantine or placebo. ${ }^{25}$

MLC601 has been reported to be helpful as an adjunctive therapy for stroke recovery. ${ }^{26}$ In this context, it could be concluded that our results are conceptually in line with these findings since stroke and $\mathrm{VaD}$ are interrelated, and stroke is a potent predictor of dementia, a meta-analysis having shown that among survivors with a recurrent stroke, the prevalence of dementia is $30 \% .{ }^{27}$ Our findings with respect to safety of MLC601 are consistent with previous studies which reported transient and tolerable adverse events. Gastrointestinal symptoms have also been reported as the most common adverse events. $^{13,14,26}$ This good long-term safety and tolerability of MLC601 is a major strength compared to the other treatments tested in $\mathrm{VaD} .^{8-10}$

There are limitations to our study. It should be mentioned that ADAS-cog score has some deficiency in detecting specific cognitive disabilities related to $\mathrm{VaD}$; therefore it 
could potentially underestimate $\mathrm{VaD}$ cognitive disability. MMSE and ADAS-cog score are widely used batteries for the assessment of cognition but the probable presence of Alzheimer's disease patients in study population cannot be excluded since the strict separation between $\mathrm{VaD}$ and Alzheimer's disease is not possible, mainly due to overlapping in their pathology. ${ }^{5,28}$ Parallel to this, it should be noted that positive results of MLC601 in Alzheimer's disease have been reported previously. ${ }^{13,14}$ In this study, we evaluated patients with conventional image modalities only (CT, MRI); positron emission tomography (PET) scanning was not carried out to identify early onset Alzheimer's disease in our patients. To the date, this is the first article reporting promising results with regard to the efficacy and safety of MLC601 in VaD patients; however further trials with larger sample size and longer follow-up period are warranted.

\section{Conclusion}

Patients with VaD treated with MLC601 showed dramatically better cognitive outcome compared to those receiving a placebo during 2 years of treatment. This study shows the excellent long-term safety and high benefit/risk ratio of MLC601 which was devoid of any serious adverse events and was well-tolerated.

\section{Disclosure}

The authors report no conflicts of interest in this work.

\section{References}

1. Fratiglioni L, Launer L, Andersen K, et al. Incidence of dementia and major subtypes in Europe: a collaborative study of population-based cohorts. Neurologic Diseases in the Elderly Research Group. Neurology. 1999;54(11):S10-S15.

2. Lobo A, Launer L, Fratiglioni L, et al. Prevalence of dementia and major subtypes in Europe: a collaborative study of population-based cohorts. Neurology. 2000;54(11):S4-S9.

3. Ott A, Breteler MM, Van Harskamp F, et al. Prevalence of Alzheimer's disease and vascular dementia: association with education. The Rotterdam study. BMJ. 1995;310(6985):970-973.

4. Baskys A, Hou AC. Vascular dementia: pharmacological treatment approaches and perspectives. Clin Interv Aging. 2007;2(3):327-335.

5. Kalaria RN, Ballard C. Overlap between pathology of Alzheimer disease and vascular dementia. Alzheimer Dis Assoc Discord. 1999;13: S115-S123.

6. van Charante EPM, Richard E, Eurelings LS, et al. Effectiveness of a 6-year multidomain vascular care intervention to prevent dementia (preDIVA): a cluster-randomised controlled trial. The Lancet. 2016; 388(10046):797-805.

7. Perry EK, Tomlinson BE, Blessed G, Bergmann K, Gibson PH, Perry $\mathrm{RH}$. Correlation of cholinergic abnormalities with senile plaques and mental test scores in senile dementia. Br Med J. 1978;2(6150): $1457-1459$

8. Narasimhalu K, Effendy S, Sim C, et al. A randomized controlled trial of rivastigmine in patients with cognitive impairment no dementia because of cerebrovascular disease. Acta Neurol Scand. 2010;121(4): 217-224.
9. Kavirajan H, Schneider LS. Efficacy and adverse effects of cholinesterase inhibitors and memantine in vascular dementia: a meta-analysis of randomised controlled trials. Lancet Neurol. 2007;6(9):782-792.

10. Orgogozo J-M, Rigaud A-S, Stöffler A, Möbius H-J, Forette F. Efficacy and safety of memantine in patients with mild to moderate vascular dementia. Stroke. 2002;33(7):1834-1839.

11. Heurteaux C, Gandin C, Borsotto M, et al. Neuroprotective and neuroproliferative activities of NeuroAid (MLC601, MLC901), a Chinese medicine, in vitro and in vivo. Neuropharmacology. 2010;58(7):987-1001.

12. Harandi A, Abolfazli R, Hatemian A, et al. Safety and efficacy of MLC601 in Iranian patients after stroke: a double-blind, placebocontrolled clinical trial. Stroke Res Treat. 2011;2011.

13. Harandi AA, Ashrafi F, Tabatabaei M, et al. Efficacy and tolerability of MlC601 in patients with mild to moderate Alzheimer disease who were unable to tolerate or failed to benefit from treatment with rivastigmine. British Journal of Medicine and Medical Research. 2013;3(2):341.

14. Pakdaman H, Harandi AA, Hatamian H, et al. Effectiveness and safety of MLC601 in the treatment of mild to moderate Alzheimer's disease: a multicenter, randomized controlled trial. Demtn Geriatr Cogn Dis Extra. 2015;5(1):96-106.

15. Pakdaman H, Amini Harandi A, Abbasi M, et al. Efficacy and Safety of MLC601 in the treatment of mild cognitive impairment: a pilot, randomized, double-blind, placebo-controlled study. Dement Geriatr Cogn Dis Extra. 2017;7(1):136-142.

16. Venketasubramanian N, Young SH, Tay SS, et al. Chinese medicine NeuroAiD efficacy on stroke recovery-extension study (CHIMES-E): A multicenter study of long-term efficacy. Cerebrovasc Dis. 2015; 39(5-6):309-318.

17. Chen CL, Ikram K, Anqi Q, et al. The NeuroAiD II (MLC901) in vascular cognitive impairment study (NEURITES). Cerebrovasc Dis. 2013;35(1):23-29.

18. Folstein MF, Folstein SE, McHugh PR. "Mini-mental state": a practical method for grading the cognitive state of patients for the clinician. J Psychiatr Res. 1975;12(3):189-198.

19. Weyer G, Erzigkeit H, Kanowski S, Ihl R, Hadler D. Alzheimer's Disease Assessment Scale: reliability and validity in a multicenter clinical trial. Int Psychogeriatr. 1997;9(02):123-138.

20. Quintard H, Lorivel T, Gandin C, Lazdunski M, Heurteaux C. MLC901, a traditional Chinese medicine induces neuroprotective and neuroregenerative benefits after traumatic brain injury in rats. Neuroscience. 2014;277:72-86.

21. Lorivel T, Gandin C, Veyssière J, Lazdunski M, Heurteaux C. Positive effects of the traditional Chinese medicine MLC901 in cognitive tasks. J Neurosci Res. 2015;93(11):1648-1663.

22. Erkinjuntti T, Kurz A, Gauthier S, Bullock R, Lilienfeld S, Damaraju CV. Efficacy of galantamine in probable vascular dementia and Alzheimer's disease combined with cerebrovascular disease: a randomised trial. The Lancet. 2002;359(9314):1283-1290.

23. Auchus A, Brashear H, Salloway S, et al. Galantamine treatment of vascular dementia A randomized trial. Neurology. 2007;69(5):448-458.

24. Wilkinson D, Doody R, Helme R, et al. Donepezil in vascular dementia A randomized, placebo-controlled study. Neurology. 2003;61(4): 479-486.

25. Wilcock G, Möbius HJ, Stöffler A, MMM 500 Group. A doubleblind, placebo-controlled multicentre study of memantine in mild to moderate vascular dementia (MMM500). Int Clin Psychopharmacol. 2002;17(6):297-305.

26. Siddiqui FJ, Venketasubramanian N, Chan E-Y, Chen C. Efficacy and safety of MLC601 (NeuroAiD $\left.{ }^{\circledR}\right)$, a traditional Chinese medicine, in poststroke recovery: a systematic review. Cerebrovasc Dis. 2013;35(1):8-17.

27. Pendlebury ST, Rothwell PM. Prevalence, incidence, and factors associated with pre-stroke and post-stroke dementia: a systematic review and meta-analysis. Lancet Neurol. 2009;8(11):1006-1018.

28. Agüero-Torres H, Winblad B. Alzheimer's disease and vascular dementia: some points of confluence. Ann N Y Acad Sci. 2000;903(1): $547-552$. 


\section{Publish your work in this journal}

Neuropsychiatric Disease and Treatment is an international, peerreviewed journal of clinical therapeutics and pharmacology focusing on concise rapid reporting of clinical or pre-clinical studies on a range of neuropsychiatric and neurological disorders. This journal is indexed on PubMed Central, the 'PsycINFO' database and CAS, and is the official journal of The International Neuropsychiatric Association (INA). The manuscript management system is completely online and includes a very quick and fair peer-review system, which is all easy to use. Visit http://www.dovepress.com/testimonials.php to read real quotes from published authors.

\footnotetext{
Submit your manuscript here: http://www.dovepress.com/neuropsychiatric-disease-and-treatment-journal
} 